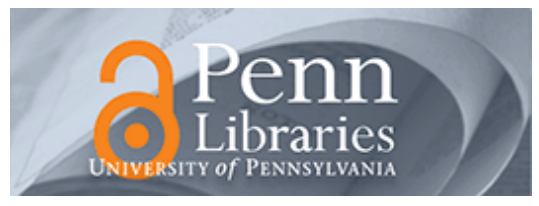

University of Pennsylvania

ScholarlyCommons

Management Papers

Wharton Faculty Research

$5-2010$

\title{
How Much to Copy? Determinants of Effective Imitation Breadth
}

Felipe A. Csaszar

Nicolaj Siggelkow

University of Pennsylvania

Follow this and additional works at: https://repository.upenn.edu/mgmt_papers

Part of the Business Administration, Management, and Operations Commons

\section{Recommended Citation}

Csaszar, F. A., \& Siggelkow, N. (2010). How Much to Copy? Determinants of Effective Imitation Breadth. Organization Science, 21 (3), 661-676. http://dx.doi.org/10.1287/orsc.1090.0477

This paper is posted at ScholarlyCommons. https://repository.upenn.edu/mgmt_papers/131

For more information, please contact repository@pobox.upenn.edu. 


\title{
How Much to Copy? Determinants of Effective Imitation Breadth
}

\begin{abstract}
It is a common and frequently implicit assumption in the literature on knowledge transfer and organizational learning that imitating practices from high-performing firms has a positive impact on the imitating firm. Although a large body of research has identified obstacles to successful imitation, not much is known about what breadth of imitation is most effective. In this paper, we use a simulation model to explore how context and firm similarity, interdependence among practices, context and firm similarity, and time horizon interact in nontrivial ways to determine the payoffs that arise from different breadths of imitation. The results of the model allow us to qualify and refine predictions of the extant literature on imitation. In particular, the results shed light on the conditions under which increases in imitation breadth, and hence investments that facilitate the faithful copying of more practices, are valuable. In addition, the results of the model highlight that imitation can serve two different functions-mimicking high performers, and generating search by dislodging a firm from its current set of practices-each requiring different organizational routines for its successful implementation.
\end{abstract}

\section{Keywords}

imitation, organizational learning, complexity, NK models

Disciplines

Business Administration, Management, and Operations 


\title{
How much to copy? \\ The contingent value of imitation capabilities
}

\author{
Felipe A. Csaszar \\ 3026 Steinberg Hall-Dietrich Hall \\ Wharton School \\ Philadelphia, PA 19104 \\ V: (215) 746-3112 \\ F: (215) 898-0401 \\ fcsaszar@wharton.upenn.edu
}

\author{
Nicolaj Siggelkow \\ 2211 Steinberg Hall-Dietrich Hall \\ Wharton School \\ Philadelphia, PA 19104 \\ $\mathrm{V}:$ (215) 573-7137 \\ F: (215) 898-0401 \\ siggelkow@wharton.upenn.edu
}




\title{
How much to copy? The contingent value of imitation capabilities
}

\begin{abstract}
It is a common (and frequently implicit) assumption in the literature on knowledge exchange and organizational learning that imitating practices from high-performing firms has a positive impact on the imitating firm. While a large body of research has pointed out obstacles to successful imitation, very little is known about what degree of imitation is most effective. In this paper, we use a simulation model to explore the role that interdependence among practices, firm-similarity, and time horizon play in influencing the value of different degrees of imitation, and show how they interact in non-trivial ways. For instance, we find that in the presence of interactions, the most effective imitation strategy between similar firms with long time horizons is the worst strategy for short time horizons. One implication of our results is that even if a firm has the capability to copy all practices from a high-performing firm, this will only occasionally be the most appropriate imitation strategy. We also show that imitation can serve two different functions - mimicking high performers and dislodging a firm from its current set of practiceseach one requiring very different organizational routines for its successful implementation. Lastly, we use the model to shed light on three previous disputes in the literature: the controversy between slow and fast learning, whether imitation is effective only at the start of operations or on a continuing basis, and whether firm similarity increases or decreases learning opportunities.
\end{abstract}

Keywords: imitation, organizational learning, complexity, NK simulation. 


\section{Introduction}

Copying ideas and practices from other, usually high-performing organizations is a widely-used mechanism employed by firms to improve their performance. Indeed, imitation is a key means of organizational learning (Argote, 1999) and has found substantial attention in the academic as well as in the practitioner-oriented literature. Imitative practices come in many forms: Among others, firms expend substantial resources to identify and imitate best practices; firms hire consultants and experts to gain access to good ideas and practices that have worked in other firms; firms invest in trade associations to share information; young firms join business incubators and seek access to well-connected venture capitalists in part with the hope to gain access to good practices used by others. On the prescriptive side, firms are exhorted to invest in capabilities that allow them to more quickly and extensively imitate others, to benchmark their practices, to implement "best practices," and to invest in absorptive capacity. The underlying rationale for these activities and prescriptions is that firms benefit from imitation.

A number of limits to the benefits of imitation are also well understood. In this context, it is helpful to distinguish two lines of argument. First, a variety of reasons exist why the act of imitating a particular practice may fail. In other words, a firm tries to copy a particular practice but is unable to do so. Reasons here include causal ambiguity (Lippman and Rumelt, 1982; McEvily, Das, and McCabe, 2000), complexity (Rivkin, 2000), lack of absorptive capacity (Cohen and Levinthal, 1990; Daley, Mehotra, and

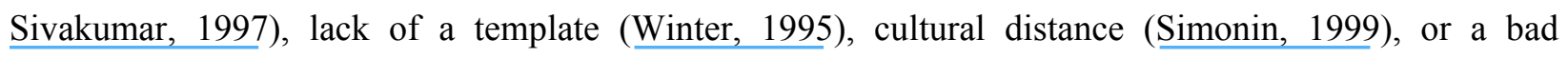
relationship to the imitated firm (Szulanski, 1996). In general, this line of work identifies barriers to imitation and suggests ways in which a firm can improve its ability to copy successfully. A second line of argument discusses why, despite the successful copying of a practice, the practice may not generate as large a benefit as expected for the firm that imitated it. Arguments here include imitation leading to similarity and consequently increased competition (Porter, 1996), and that the copied practice may in reality have little economic value even though it is celebrated in its industry (Staw and Epstein, 2000). 
Given that prior work has either posited that imitation is generally valuable, or has argued that imitation creates no benefit, the question of what is an effective degree of imitation has received relatively little attention. (The prior views would simply imply the extremes of "maximum degree of imitation" and "no imitation at all.") As a result, very little is known about the conditions in which it may be advisable to engage in small, intermediate, or very large imitation attempts. Our paper attempts to shed light onto this problem. In particular, we focus on the interplay among three conditions that have been highlighted in the existing literature on imitation: a) the time horizon over which a firm seeks to achieve improvements, b) the degree of interaction between the practices of a firm, and c) the similarity between the source and the recipient of the copied practices. While the latter two factors have been identified to influence the difficulty of imitation, their impact on which degree of imitation is most valuable has not been studied.

Methodologically, we use an agent-based simulation model that contains firms which differ in their capability to imitate practices from high-performing firms. Using a simulation allows us to study the effects of imitation in a systematic manner and to identify underlying mechanisms that shape how an increase in imitation capability affects performance in different environmental conditions. Among our results, we find that the most effective breadth of imitation differs significantly depending on the relevant time horizon. What may be ideal for short time horizons may be very poor for long time horizons, and vice versa. More fundamentally, we show that imitation can serve two different functions in helping a firm to improve its performance: mimicking the practices of a high-performing firm and dislodging the firm from its current set of practices. Organizationally, these two functions require very different routines, implying that managers need to be aware of which function they would like imitation to play in their organizations. Finally, we use the model to shed light on three previous disputes in the literature: the controversy between slow and fast learning, whether imitation is effective only at the start of operations or on a continuing basis, and whether firm similarity increases or decreases learning opportunities.

The paper proceeds as follows: Section II reviews the literature, Section III presents the model, Section IV analyzes the model and derives results, and Section V describes limitations and discusses how the model can shed light on existing controversies in the imitation and learning literatures. 


\section{Prior work on imitation}

Imitation is pervasive - both as a concept in the academic literature and in practice. As Lieberman and Asaba (2006:366) have noted, "imitation of superior products, processes, and managerial systems is widely recognized as a fundamental part of the competitive process." Supporting this notion, Nutt (1998) empirically found that importing knowledge from other firms is one of the most frequently used tactics to solve problems. A large and diverse literature exists that, explicitly or implicitly, argues for benefits of imitation. The explicit literature argues directly why imitation is beneficial. The implicit literature shows how imitation barriers can be overcome, assuming implicitly that imitation is valuable. Given the wide range of literatures that touch on imitation, including institutional theory, organizational learning theory, and network theory, the following overview should be seen more as impressionistic than as comprehensive.

In situations of uncertainty, companies may look to other companies' behavior for guidance and imitate their actions. In these circumstances, imitation can be beneficial for two reasons. First, as companies are concerned with staying in tune with the norms and conventions of their industry, imitation or mimetic isomorphism may increase the legitimacy of a firm (DiMaggio and Powell, 1983). Second, imitation allows a firm to economize on search and communication costs. In the words of Lieberman and Asaba (2006:373), “in highly uncertain environments, where quick action is necessary, imitating others becomes an attractive decision rule.”

The literature on benchmarking - one of the clearest instantiations of willful imitation-provides further evidence of the wide-spread extent of imitative activities. For instance, Szulanski (1996:27) noted that "the identification and transfer of best practices is emerging as one of the most important and widespread practical management issues of the latter half of the 1990s," while Argote (1999:146) argued that 'the popularity of 'benchmarking' and programs to transfer 'best practices' or 'lessons learned' from one organization to another reflect the usefulness of acquiring knowledge from other firms."

Various mechanisms have been described that allow firms to increase their ability to benefit from knowledge that resides outside their organizational boundaries, with the implicit assumption that utilizing 
such outside knowledge will be beneficial for the firm. For instance, many alliances are explicitly created to increase access to ideas and technologies developed by others, allowing firms to speed up the development of their capabilities (Kogut, 1988; Mowery and Sampat, 1999). Likewise, young firms join business incubators and seek access to well-connected venture capitalists in part to gain access to good practices by others (Bollingtoft and Ulhoi, 2005). Lastly, the discussion of which type of network structure-for example, dense networks versus small-world networks (Schilling and Phelps, 2006) allows for the most productive information flow, generally assumes that gaining more access to information and having the ability to copy and assimilate information thus gathered is a valuable undertaking. Relatedly, the literature on structural holes (e.g. Burt, 1992) emphasizes that information brokers are valuable because they allow information interchange between otherwise disconnected networks. Implicit in this argument is that the transfer (or imitation) of information among the parties is valuable.

The general tenor of the literature discussed so far is that there exists an increasing value in the capability to access more information and to copy more practices of high-performing firms. While a large literature has dealt with the question of why imitation of a particular practice may fail or be difficult, i.e., the case in which a firm tries to copy practice A but is unable to do so, or ends up only with practice A' (see for example Lippman and Rumelt (1982) on uncertain imitability, and Ounjian and Carne (1987) on causal ambiguity), another, stream of work has discussed the limits to the benefit of successful imitation, i.e., the case in which a firm was able to copy practice A, yet little or no benefit accrued to the firm (e.g. Lieberman and Montgomery, 1988). Two arguments in this last line of research are as follows. First, as firms copy more practices from each other, strategic convergence ensues, decreasing differentiation among firms, increasing competition, and consequently leading to profit erosion (Porter, 1996). Second, the copied practices, while held up in the industry as "key success factors" may actually not be economically valuable. For example, Staw and Epstein (2000) showed that companies associated with popular management techniques did not have higher performance, but nevertheless were more admired, 
perceived to be more innovative, and offered a higher pay to their chief executives than firms not associated to these techniques.

With these caveats in mind, then, prior work on imitation suggests:

Proposition: Assuming a firm is able to successfully copy practices from other firms, and assuming that no competitive effects exist and that the copied practices were valuable to the imitated firm, the ability to copy more practices from high-performing firms is beneficial.

The main goal of our paper is to probe more deeply into conditions that may influence the most effective degree of imitation, and hence the value of imitation capabilities. In particular, our focus is on three contingency variables that have been prominently featured in the work on imitation, yet whose role in affecting the value of different degrees of imitation has not been investigated: complexity, the time horizon over which benefits accrue, and similarity between firms.

A substantial literature has argued that complexity increases the difficulty of imitation. Empirical studies include Ounjian and Carne (1987), who observed that increased complexity reduced the rate of diffusion of innovations in a large organization. Likewise, Galbraith (1990), in the context of manufacturing plants, found that the time to successfully adopt an innovation increased with the complexity of the innovation. Using a simulation model, Rivkin (2000) showed more formally how interactions among a firm's activities can create formidable barriers to imitation. In particular, Rivkin (2000) fixed the level of imitative capability (at some non-perfect level) and found that as complexity increased, imperfect imitation became more and more costly. Thus, this paper highlighted the importance of complexity in the context of imitation, but was silent on the value of different degrees of imitation. In a related paper, Rivkin (2001) analyzed the advantages that a firm which replicates its practices might have over a firm that tries to imitate these practices. Rivkin (2001) showed that a fixed difference in the likelihood of correctly imitating practices creates particularly high benefits for intermediate values of complexity. Thus, this paper illustrated a particular instance in which a higher imitation capability had a positive value. As we will show, taking into account different time frames, different degrees of inter-firm 
similarity, and studying systematically a broader range of imitation capabilities, reveals previously unidentified interactions in the value of imitation capabilities, including cases in which better capabilities can backfire.

A second, prominent contingency factor is the time horizon that a firm deems relevant for its imitative activities to bear fruit. In some industries, for instance, in high-tech, shorter horizons are common, while in others, say in the oil industry, longer time horizons become important. Frequently, the issue of the relevant time horizon is couched in terms of the turbulence of the environment. In turbulent environments, relevant time horizons become shorter. Actions that lead to quick performance improvements for a given environment are more valuable than actions that might lead to a higher performance in the long run, since the long run may never occur in this particular environment (the environment will have changed by then).

The third contingency factor we consider is the degree of similarity between the firm that imitates and the firm that is imitated. There are different views on the value of similarity in the context of imitation. One view is that differences increase learning opportunities. This view was early noted by Mill (1848/2004:543): "It is hardly possible to overrate the value [...] of placing human beings in contact with persons dissimilar to themselves, and with modes of thought and action unlike those with which they are familiar [...] Such communication has always been, and is particularly in the present age, one of the primary sources of progress." This view finds an echo in the brokerage literature (Burt, 1992), that stresses the value of people who can connect dissimilar networks.

On the other hand, a different line of research states that firms may only be able to learn from others when their resource endowments are similar (Lieberman and Asaba, 2006). For example, Helfat (1997) showed that only firms with expertise in oil refining R\&D could adopt innovations related to synthetic fuels; likewise, Lane and Lubatkin (1997) found that the similarity between firms' knowledge bases was an important determinant of imitation success. Using a simulation model, Gavetti, Levinthal, and Rivkin (2005) obtained similar results: the value of analogies (transferring ideas from one context to another) decreased as the similarity between the contexts declined. Thus, again, a considerable literature has 
pointed to a particular variable as an important factor for the value of imitation (in this case "similarity"), yet little is known about how this variable affects the most effective degree of imitation.

\section{Model}

Our goal is to assess the benefits of different degrees of imitation capabilities over different time horizons and between firms that differ in similarity, in the presence of interactions among the practices that are copied. To do so in a systematic manner, we develop a simulation model in which we have direct control over these three contingency factors. In the model, managers of firms seek to find good combinations of practices. Managers can engage in a local search process or engage in imitative behavior. In particular, we study the benefits of different degrees of imitative capabilities by varying the number of practices firms can imitate simultaneously at any given point in time.

\section{III.1. Interactions among practices}

The starting point of our model is the conceptualization of firms as systems of interdependent practices (Porter, 1996; Siggelkow, 2002). Each modeled firm is assumed to make $N$ binary decisions about how to configure its practices. $N$ reflects the fact that a real firm must make numerous decisions, for instance, whether or not to increase the price for its product, whether or not to locate a new store at a particular location, or whether or not to outsource a particular production activity. We represent a firm's configuration of practices as $\mathbf{d}=d_{1} d_{2} \ldots d_{N}$ with each $d_{i}$ either 0 or 1 .

To account for the possibility of interactions among the practices of a firm, the payoff or contribution of a practice is modeled as a function of the practice itself and the resolution of $K$ other practices. $K$ is thus a measure of interdependence. If $K=0$, the contribution of each practice is independent of how the other practices are configured. At the other extreme, if $K=N-1$, the contribution of each practice would depend on how all other practices within the firm are configured.

The contribution function for a particular practice is a mapping of all relevant practice configurations to payoff values. For instance, in the case of two activities $(N=2)$, with $K=0$, the contribution function 
for activity 1 would have two values: $c_{1}(0), c_{1}(1)$, i.e., the payoff to practice 1 if practice 1 is configured as " 0 ", or as " 1. " Likewise, the contribution function for activity 2 would have two values, $c_{2}(0)$ and $c_{2}(1)$. If $K=1$, each contribution function would have four entries: $c_{1}(00), c_{1}(01), c_{1}(10)$, and $c_{1}(11)$, denoting the payoff to practice 1 if both practices are configured as " 0 "; practice 1 is configured as " 0 " and practice 2 configured as " 1 "; etc. Likewise for $c_{2}(\cdot)$. The firm's overall performance $P$ is then given by the average across the contributions. For instance, if the firm had chosen the practice configuration 01 , then $P=\frac{1}{2}\left[c_{1}(01)+c_{2}(01)\right]$. Lastly, all entries $c_{i}(\cdot)$ for each contribution function are drawn independently from a uniform distribution over the unit interval.

This procedure for generating payoff functions - stochastically, but with well-controlled patterns of interaction-is adapted from Kauffman's (1993) NK model, a model originally developed in the context of evolutionary biology. Numerous management scholars have used this procedure in recent years to generate payoff functions that can be employed to examine organizational search (for instance, Levinthal, 1997; McKelvey, 1999; Gavetti and Levinthal, 2000; Marengo, Dosi, Legrenzi, and Pasquali, 2000; Rivkin and Siggelkow, 2003; Ethiraj and Levinthal, 2004; Lenox, Rockart, and Lewin, 2006, and references therein). It is common to interpret such payoff functions in terms of high-dimensional performance landscapes. Each of the $N$ decisions constitutes a "horizontal" axis in a high-dimensional space, and each decision offers different options. Resulting from each combination of choices is a payoff for the firm, which is plotted on the vertical axis. The goal of organizational search is to find and occupy a high spot on this landscape, i.e., to select a combination of choices that, together, are highly successful. Interactions among decisions cause the landscape to become rugged and multi-peaked, making the search for a high peak eminently more difficult (Kauffman, 1993; Rivkin, 2000).

\section{III.2. Similarity between firms}

To explore the effects of imitation between $M$ firms that have a certain degree of similarity, we need to be precise about what we mean by "similar." For the purpose of studying the value of imitation, 
similarity should reflect the degree to which practices that work in one context are likely to work in another context. As a result, we operationalize similarity as the extent to which an identical set of practices implemented by different firms leads to similar levels of performance. Thus, the more similar the performance that two firms achieve with the same set of activities, the more similar are the firms. To model this, we developed a mechanism to create correlated performance landscapes, with each firm "living" on its own landscape. When similarity is maximal, all landscapes are identical, and hence, firms implementing the same set of practices achieve the same level of performance. As similarity decreases, the correlation between the performances generated by identical sets of practices decreases. At the extreme, with no similarity, the correlation becomes zero.

In the model, this is implemented as follows. Similarity, $S$, is modeled as a number between 0 and $N$ that describes how many contribution functions are shared between firms. Hence, if $S=0$ the landscapes are completely unrelated; if $S=N$, landscapes are identical. For intermediate values, $S$ practices and their contribution functions are randomly picked and assumed to be shared by all firms.

The following equations describe an example with $M=3$ firms, each one making three decisions ( $N=3$ ), each decision depending on one other decision $(K=1)$, and two shared contribution functions $(S=2)$ :

$$
\begin{aligned}
P^{1}\left(d_{1}^{1}, d_{2}^{1}, d_{3}^{1}\right) & =\frac{1}{3}[\overbrace{c_{1}\left(d_{1}^{1}, d_{2}^{1}\right)+c_{2}\left(d_{2}^{1}, d_{3}^{1}\right)}^{\text {shared }}+c_{3}^{1}\left(d_{3}^{1}, d_{1}^{1}\right)] \\
P^{2}\left(d_{1}^{2}, d_{2}^{2}, d_{3}^{2}\right) & =\frac{1}{3}\left[c_{1}\left(d_{1}^{2}, d_{2}^{2}\right)+c_{2}\left(d_{2}^{2}, d_{3}^{2}\right)+c_{3}^{2}\left(d_{3}^{2}, d_{1}^{2}\right)\right] \\
P^{3}\left(d_{1}^{3}, d_{2}^{3}, d_{3}^{3}\right) & =\frac{1}{3}\left[c_{1}\left(d_{1}^{3}, d_{2}^{3}\right)+c_{2}\left(d_{2}^{3}, d_{3}^{3}\right)+c_{3}^{3}\left(d_{3}^{3}, d_{1}^{3}\right)\right],
\end{aligned}
$$

where $P^{i}$ is the performance of firm $i, c_{j}^{i}$ is the contribution function for practice $j$ of firm $i$ (if the superscript $i$ is not present, then this is a shared contribution function), and $d_{j}^{i}$ is the choice of practice $j$ by firm $i$. Thus, in this example, if the firms made identical choices with respect to their practices $\left(d_{1}\right.$, $d_{2}$, and $d_{3}$ ), all three firms would get the same contributions from practices $d_{1}$ and $d_{2}$, yet different contributions from practice $d_{3}$. 


\section{III.3. Local and imitative search}

Firms attempt to find combinations of practices that yield high performance. To this end, they can engage in local or imitative search. Building on the work of Simon on bounded rationality (Simon, 1947; Cyert and March, 1963), search is often seen as occurring via evaluation of alternatives that are close to the current status quo. In particular, we model local search as testing all local alternatives, i.e., alternative practice configurations that differ in only one practice, and choosing the one with the highest performance. For instance, if $N=2$, and the status quo choices are 00 , then the firm would evaluate alternatives 01 and 10 (but not choice 11), and choose the configuration with the highest performance. For instance if $P(01)>P(00)>P(10)$, the firm would chose 01 . This configuration would then be the starting point for further search in the next period. An intrinsic problem of local search is that it can get stuck on a local peak before reaching the global peak of the landscape (Levinthal, 1997).

To escape the bounds of local search, firms can engage in imitating other organizations. We model two different ways in which imitative search can take place: discriminant and non-discriminant imitation. Both types of imitation involve copying information from a template firm to a recipient firm, "moving" the recipient firm to a new position on its landscape. Given that the leading firms in an industry often serve as templates for imitation (e.g., Haveman, 1993), the best performing firm among the $M$ simulated firms is chosen as the template firm. ${ }^{1}$

Discriminant and non-discriminant imitation differ in how much firms know about the similarity between the template and the recipient firm. Discriminant imitation assumes that the recipient firm knows the identity of the practices that it shares with the template firm (i.e., those practices for which the two firms have the same contribution functions). In this case, if the recipient firm has the capability to copy $\phi$ practices, it will randomly select $\phi$ practices from the shared dimensions and copy them. With nondiscriminant imitation the recipient firm does not know which practices it shares with the template firm.

\footnotetext{
${ }^{1}$ In order to compare the performances of firms that live on different landscapes and to chose the best performer, performance is normalized to the range $0-1$, where 1 is the global peak of that landscape, and 0 the global minimum of that landscape.
} 
In this case, if the firm has the capability to copy $\phi$ practices, it randomly chooses $\phi$ practices from the $N$ practices of the template firm and copies them. The minimum value that $\phi$ can take is zero (nothing is copied). The maximum value for $\phi$ under discriminant imitation is $S$ (copy everything that is shared), and $N$ under non-discriminant imitation (completely copy the other firm's practices). Non-discriminant imitation may describe circumstances where severe causal ambiguity is present, making the source of the performance advantage of the leader not clear from the perspective of the imitator. In contrast, discriminant imitation is a more informed imitation, where the imitation is directed to the part of the business that has been previously identified to be shared between the firms. In the model, either way of imitating takes one time period to happen.

In sum, $\phi$ represents a firm's imitative capability ${ }^{2}$ : if $\phi$ is low, a firm can imitate just a few decisions from high-performing firms at a time; if $\phi$ is high, a firm can imitate many decisions at a time. Discriminant and non-discriminant imitation represent the extent to which a firm knows what is shared with high-performing firms: under discriminant imitation, only shared business decisions can be copied, under non-discriminant, any decision may be copied. One should also note that the simulation helps to control for the two caveats mentioned in the above Proposition. In our model, imitation does not have a negative competitive effect. Similarly, by construction, practices are indeed linked to performance and are not simply copied for ceremonial purposes.

In the simulation, in each time period, firms perform a local search until they cannot improve their performance, i.e., get stuck. Once stuck, a firm will perform an imitative search in the following period, that is, the firm will copy information from the highest performing firm, either using discriminant or nondiscriminant imitation (depending on the model). After this imitation, the firms continue to perform local searches until stuck again, at which point they would imitate again, etc. The imitation can be seen as a long jump in the landscape, and can be interpreted as exploration since it allows firms to explore

\footnotetext{
${ }^{2}$ In the model we assume that imitative capabilities are used to their full extent. Another interpretation of $\phi$ is that it is the extent to which an imitative capability is used.
} 
strategies that are quite distant from the current one. The subsequent local searches can be interpreted as more fine-grained adjustments to the new set of routines to further improve performance.

\section{$\underline{\text { III.4. Implementation Details }}$}

At the beginning of each simulation run, a new landscape was created and firms were placed on random locations, i.e., were endowed with random practice configurations. Each simulation was run for 100 time periods. This time frame was chosen because for the range of parameters employed, this proved to be enough time for all firms to achieve a steady state (they are either stuck or they engage in a repetitive cycling behavior). In other words, $T=100$ can be understood as a long-term equilibrium situation.

In order to report results that are caused by the nature of the model and not by any specific randomly generated landscape, the results for each set of parameters were computed by averaging 1,000 simulation runs. All reported results are significant at the $5 \%$ level.

\section{Results}

The main goal of our analysis is to study the performance effects of higher abilities to imitate, i.e., of being able to copy more practices from the highest performing firm. To this end, we vary the extent of imitation $(\phi)$ over its entire range in every model that we analyze. To assess the effects for different time horizons, we report performance values for periods 10 and 100 (the results are not sensitive to these exact time periods). In the first set of simulations, the focus is on firms that are similar to each other while we vary the degree of interdependency among the practices. In the second set of simulations, we study firms that are dissimilar from each other.

Even though the model is relatively parsimonious (it depends on only five parameters) it would be very unwieldy to describe the results of all combinations and gradations of these five parameters. Hence, we resort to describing representative cases that we identified after carefully exploring the space of possibilities and after testing for the robustness of the findings. Specifically, we keep the number of 
decisions $(N)$ fixed at 12; the number of firms $(M)$ fixed at 5; and landscape complexity $(K)$ and landscape similarity $(S$ ) take a low and a high value ( 2 and 10 for $K$, and 4 and 12 for $S$ ).

\section{$\underline{\text { IV.1. Imitating similar firms }}$}

We start the analysis by studying the effects of imitation in the "simplest" type of environment: firms are similar to each other, and each firm's practices are not very interdependent. In particular, firms face identical landscapes ( $S=12$, i.e., they share all 12 contribution functions that define performance) and the complexity of the landscapes is low $(K=2)$.

Figure 1 shows the effect on performance of varying the degree of imitation, with $\phi$ going from 0 to 12, i.e., from not imitating at all to perfectly imitating the best performer. The effect is measured for the short and long term ( $T=10$ and 100 respectively).

We will first discuss the short term curve of Figure 1. In agreement with the literature, this curve has a clear upward slope: the more practices are copied, the higher the performance of a firm. Thus, in this case, the ability to imitate more practices is indeed a valuable capability for a firm. Interestingly, at very high levels of imitation (when $\phi>8$ ) the performance improvement due to imitation is slight. This happens because even if valuable information is not copied, it can be re-created by the imitator by performing local searches after the imitation.

\section{$<$ Insert Figure 1 about here $>$}

The long term curve tells a somewhat different story. In contrast to the short-term curve, the longterm curve ascends very rapidly. The marginal payoff of going from not imitating at all to imitating one or two practices is very high, since given enough time, imitating just one or two practices each time the firm is stuck suffices to dislodge the firm from its current local peak and enables it to find a higher peak. A real-world example would be a firm that has ceased to improve its profitability and decides to imitate a simple customer-service process from a similar competitor. Sometimes copying such process will be a mistake; but because the extent of the imitation is small, it is easy to reverse the changes. Other times the copied process will be equivalent to the process already in practice, so there will be no change in 
performance. And in other cases, the imitated process, either immediately or after a few local tweaks, will improve performance. Thus, on average, in these circumstances (high similarity and low complexity) even copying few practices will add value. ${ }^{3}$

A final observation about the long-term curve is that it achieves its maximum around $\phi=5$ and from then on descends very slowly. ${ }^{4}$ This happens because by copying large numbers of practices from the current best performer, the firm is limiting its possibilities of finding a better peak than the one occupied by the current best performer. In the extreme, if the whole industry is always imitating what the best performer does, there will be many unexplored opportunities because no one will dedicate resources to innovating, potentially leading to pathological scenarios (Bikhchandani, Hirshleifer, and Welch, 1998; Lieberman, 2002). ${ }^{5}$

Up to now, the imported practices were relatively context-free or self-contained ( $K$ was low). What happens when we increase complexity? Figure 2 is analogous to Figure 1 but under a highly complex environment $(K=10)$. With a high degree of interdependence among firms' practices, quite different results arise. Considering short-run performance first, we can observe a marked non-monotonicity: a moderate level of imitation $(\phi=3)$ is worse than both no imitation at all and a high degree of imitation.

In the short run, imitation of only a few practices of the best performer is detrimental because due to the interdependencies among the practices, the imported practices are likely to be incompatible with the rest of the firm's practices. If the firm imitates only one or two practices, the firm may be able to undo these changes if necessary. If the firm imitates three of four practices, the firm is unlikely to find its way

\footnotetext{
${ }^{3}$ As an aside, one may note that the performance for $\phi=0$ is practically the same for the short and long term since $\phi=0$ implies that these firms can only perform local searches, and given that firms make choices with respect to 12 practices, the great majority of firms will already be stuck at a local peak at $T=10$ (the short term). Thus, both in the short and long term the firm will be at the same local peak when $\phi=0$.

${ }^{4}$ The long-run performances for $\phi=5$ and $\phi=12$ are statistically different from each other at the $5 \%$ level. Since performances were not normally distributed, we used a Monte Carlo permutation test and not the standard t-test (Efron, 1979). All the results presented in this paper were verified using a similar procedure.

5 Our simulation also points to an exception to this pathological behavior: if the best performer has already found the global peak, high imitation is the best firms can do. However, this scenario is unlikely in the real world, as it may only happen if the landscape is very smooth (e.g., $K=0$ ) or the number of firms is very high ( $M$ approaches the number of locations of the landscape, $2^{N}$ ). (Results available from the authors.)
} 
back to its old set of practices. Only when larger "chunks" of practices are imported does the short-run effect on performance turn positive, because many of the interactions of the imported practices will fall within that chunk. Figure 3 illustrates this effect by measuring the percentage of imitations that end up decreasing performance in the short run. The measure includes not only the performance change due to the imitation, but also due to the subsequent local searches (until the next imitation). In other words, we measured the effect of the imitation plus all the subsequent local refinements. As can be seen in Figure 3, the relationship between the percentage of imitations that end up decreasing performance and the degree of imitation $(\phi)$ has an inverted $U$ shape.

Another interesting characteristic of the short term curve in Figure 2 is that its peak happens when almost everything $(\phi=10)$, but not all practices, are copied. Not copying everything allows the firm to search for a peak that is even higher than that of the current best performer. Should that search be unsuccessful, the firm would still be able to re-create the not copied practices of the best-performing firm with a few local searches and reach the peak of the best performer.

Summarizing, in the short term, an increase in imitative capabilities is not always valuable since intermediate-sized imitations are not beneficial among similar firms. Firms are better off engaging in small changes that do not disrupt too many practices and that allow them to recover quickly if needed, or, if they have the capability to do so, by engaging in large-scale imitations that capture many of the interdependencies among the copied elements. ${ }^{6}$

\section{$<$ Insert Figures 2 and 3 about here $>$}

The long-run curve in Figure 2 also shows a distinct non-monotonicity. Interestingly, what is worst for short time horizons (an intermediate level of imitation) is what is best for long time horizons. What explains the high long-run performance generated by intermediate sized imitations? In the presence of

\footnotetext{
${ }^{6}$ These findings are consistent with Rivkin's (2001) results. In his model, firms live on the same landscape, conduct only one imitation and subsequently engage in local search. This closely resembles the behavior of our firms by period 10, i.e., our short-run performance. The (implicit) levels of $\phi$ that Rivkin (2001) studies lie all in the upwardsloping part of Figure 2, i.e., they do not capture the possibility of decreasing performance as $\phi$ increases from very low levels.
} 
many interdependencies, the performance landscape becomes very rugged, offering many peaks on which firms may get stuck. This ruggedness, hence, increases the value for exploration of firms. At one extreme, if a firm engages in only small imitations, a firm may not be able to escape from its current peak, that is, from its current set of practices. (More formally, it is unable to leave the basin of attraction of its current local peak.) For short time horizons, this may be beneficial, as most small imitations are detrimental. For long time horizons, however, such small changes do not provide the firm with the possibility to reach higher peaks, i.e., to find better-performing configurations of practices. At the other extreme, as a firm copies a very large number of practices, overall exploration of the firm declines as well. For instance, were a firm to copy all 12 practices of the best-performing firm (and assuming that that firm is on a peak), the imitating firm would never explore any further configurations of practices. Figure 4 confirms this intuition. Here we plot the average number of configurations of practices (or, equivalently, locations on the landscape) that firms experience over their 200-period life span. As we can see, exploration is maximized in the long run by intermediate sized imitations - large enough to allow a firm to escape from its current configuration, but small enough to avoid locking in the firm too quickly on the currently best configuration of the industry (which may not be the best achievable).

\section{$<$ Insert Figure 4 about here $>$}

In sum, our results concerning imitation among similar firms provide some boundary conditions to the general notion that the capability to imitate more practices from high-performing firms is valuable. Even in the absence of competitive effects, it is rarely optimal to imitate to the maximum extent possible. These results also shed light on the controversy between the advocates of slow learning (Levinthal and March, 1981; Herriott, Levinthal, and March, 1985; March, 1991) and of fast learning (Eisenhardt and Tabrizi, 1995). When firms are concerned with short time horizons (e.g., because they live in turbulent environments), then fast learning through broad imitation (high $\phi$ ) is a valuable strategy. However, fast learning is not always advisable. For example, in complex environments, increasing a firm's imitative capabilities from zero to a small level may actually be counterproductive for short-run performance. In contrast, when firms are concerned with long time horizons, e.g., when operating in more stable 
environments, intermediate levels of imitation, or slower learning, tends to be optimal. Figure 5 summarizes the findings regarding the most effective degree of imitation between similar firms.

\section{$<$ Insert Figure 5 about here $>$}

\section{$\underline{\text { IV.2. Imitating dissimilar firms }}$}

In the previous section, imitation was performed among firms that were very similar, i.e., that faced the same performance landscape. In this section, we study firms that are dissimilar. An understanding of the effects of imitating firms that face different performance landscapes might be important, because in many circumstances firms may not have directly comparable peers. For example, an early startup in an innovative industry (e.g., iRobot in the household robots industry), an organization facing a unique task (e.g., the Justice Prisoner and Alien Transportation System in the US), and many oligopolistic firms serving unique markets (e.g., Hindustan Lever selling a broad range of consumer goods in India) do not have peers facing exactly the same landscape, but firms with varying degrees of similarity which may be candidates for imitation.

We explore the effects of imitation among firms that face performance landscapes that are neither completely identical nor completely different, but have an intermediate degree of similarity. In the following analyses, this is modeled by reducing the number of shared contribution functions $(S)$ from 12 to 4. Our analysis follows the same scheme as in the previous section: we explore the effects on performance of varying the extent of imitation $(\phi)$ in the short and the long run, on both low and high complexity landscapes (Figure 6 and Figure 7, respectively). It is important to note that now the range of values that imitation $(\phi)$ can take is constrained by the degree of similarity $(S)$, since discriminant imitation is only defined for $\phi \leq S$; if firms only share $S$ practices they can at most imitate $S$. (In the next section, we will study non-discriminant imitation, which does not have this constraint.)

\section{$<$ Insert Figures 6 and 7 about here $>$}

The most striking feature of these new figures is that for each one of the four curves shown, the best performance is achieved at $\phi=0$. In other words, when similarity is low, the best decision is to avoid 
imitating others. This happens because even if a practice has only few interactions, most of these interactions will be with practices that are not shared. In other words, the imported practices will not be compatible with the unique characteristics of the recipient. This is very much akin to the short-run results we saw for imitation among similar firms in complex environments.

Why does intermediate-sized imitation not work even in the long run, as it did for similar firms? With dissimilar firms, the problem is that the range of practices that can be copied is narrower. With similar firms, over time up to 12 practices of a leading firm can be copied (in chunks say of $\phi=4$ ). With dissimilar firms, a total of only $S$ (in our case 4) practices can be copied. If the best performer remains the same, an imitating firm with $\phi=4$ would always copy the same set of practices from the best performer again and again. In this case, imitation does not only fail to import valuable practices, but it also fails to create variety of new ideas.

Note that the previous results do not imply that imitation among dissimilar firms is always a bad idea. Apart from lucky imitations, there are at least two cases for which the previous results do not hold: in very low complexity landscapes (e.g., $K=0$ ) and under modular interactions. If $K$ is very low, the imported information is completely self-contained, so a valuable imitated practice continues to be valuable in the receiving firm. (Indeed, when we run our simulation with $K=0$, all firms regardless of $\phi$ reach the global peak. Firms with higher values of $\phi$ reach the global peak faster, though. Results are available from the authors.)

The second case not covered in the previous figures is imitation of shared "modules." Modularity means that all (or more generally, almost all) interactions of a set of practices fall within that set of practices. Or conversely, modularity means that there are no (or only few) interactions between different modules. Hence, an imitation of a shared module can be thought of as an imitation between smaller firms (the size of the module) that share all their practices. (See also Ethiraj, Levinthal and Roy (forthcoming), who show that modularity eases imitation significantly.) One example of imitating a shared module could be the Justice Prisoner and Alien Transportation System adopting the engine maintenance practices of 
American Airlines. Clearly both organizations are different, but probably their engine maintenance practices can be imitated because they are shared and modular. Hence, the results of the previous section concerning imitation between similar firms are applicable to imitation between shared modules of otherwise dissimilar firms.

\section{IV.3. Non-discriminant imitation}

Until now, imitation has been modeled as discriminant imitation which assumed that the imitating firm has a clear understanding of what is shared with the target firm. What happens if there is causal ambiguity, and the imitating firm does not clearly know what is shared? Can imitation add value under these circumstances?

Figure 8 presents the four main charts of our analysis, under non-discriminant imitation instead of discriminant imitation. The upper two panels of the figure are identical to the figures that showed the effects of discriminant imitation when all practices were shared (Figures 1 and 2); there are no surprises here, since by definition, non-discriminant imitation renders into discriminant imitation when $S=N$ (both copy $\phi$ out of $N$ practices).

The bottom two panels of Figure 8 show the results of imitation between dissimilar firms. Given that the identity of the shared practices is not known, firms might copy up to 12 practices from the best performer. Thus, $\phi$ can lie between 0 and 12. The curves for short time horizons lead to the same conclusion as under discriminant imitation: for dissimilar firms, no imitation dominates any amount of imitation. For short time horizons, the newly adopted practices are likely to create misfits with the existing practices and lead to performance deterioration.

For long time horizons, however, results differ significantly. We observe an inverted U shape: when similarity is low, small degrees of imitation (in these examples, $1 \leq \phi \leq 3$ ) and enough time allow the firm to achieve a higher performance level. At first, this result may seem surprising: imitating small parts of markedly different firms can be beneficial if firms do not constrain themselves to copy only from the set of shared practices. The explanation is that in loosening this constraint, valuable variety is generated. The 
argument is analogous to the explanation of why under high similarity and high complexity small doses of imitation were useful: importing small doses of new practices is valuable in the long run because they can dislodge the firm from a local peak, increase its exploration, and enable it to find a new, higherperforming configuration of practices. Figure 9, showing the average number of locations visited by firms supports this intuition; small-scale imitation ( $\phi$ around 3) leads to the largest extent of exploration.

This last finding leads us to a speculative observation. The academic literature frequently tends to question the value of "airport-store business books," yet there seems to be a large market for them. Are managers just naïve, or do these books actually provide value? Our findings suggest that as long as only small-scale changes are implemented, these changes can still provide value in the long run even though the new ideas may not be valuable per se. The effect of spurring the firm to change its sets of practices can renew the firm's search effort, and given enough time, allow the firm to reach a higher-performing set of practices. Figure 10 summarizes our findings regarding the most effective degree of imitation between dissimilar firms.

\section{$<$ Insert Figures 8, 9, and 10 about here $>$}

\section{Discussion}

We used our simulation model to systematically explore the value of increasing a firm's imitative capabilities. In particular, we studied three contingency factors-complexity, similarity, and time horizon-and their interactions. The most effective level of imitation is dependent on these three parameters in non-trivial ways. Interestingly, the capability to copy large numbers of practices is valuable only when there are similar peers and when the time horizon is short. All other scenarios do not call for maximum imitation.

Our work unearths two functions of imitation: imitation as a way to mimic high-performers and imitation as a way to dislodge a firm from its current set of practices. The following examples clarify this distinction. A firm in a low complexity environment with a high-performer similar to itself should opt to copy, if possible, a substantial number of practices from the high-performer, that is, to mimic a highperforming firm. On the other hand, a firm on a complex landscape with enough time to experiment 
should opt to import only small chunks of information from others, that is, to dislodge itself from its current set of practices. Mimicking and dislodging can both be achieved by imitating others; but conceptually and pragmatically they are two distinct strategies. To start, they both require radically different organizational commitments. Mimicking requires imitation of large chunks of practices with high fidelity; hence it requires mechanisms to assure the quality of the imitation. On the other hand, dislodging does not require high fidelity nor copying large chunks of information, but an organizational commitment to plasticity. Dislodging requires imitating small chunks and then adapting subsequently in order to reach a better configuration of practices. It also requires alertness, because if the firm cannot discover a better configuration subsequent to the imitation, it has to rapidly undo the changes caused by the imitation. In other words, mimicking seeks to drive out variance, while dislodging seeks to create variance. Consequently, the organizational commitments of both imitation strategies are opposed: one requires strict enforcement of rules while the other one is more an exercise in creativity. This implies that if a firm tries to mimic but is in a "dislodging mode," the imitation might likely fail, and vice versa. A further distinction is that both mechanisms react differently to information which is difficult to copy. For example, tacit knowledge, which is difficult to copy with fidelity, would seriously undermine the success of mimicking but not of dislodging. Figure 11 reframes the 2-by-2 matrices of Figures 5 and 10 as a decision-tree that suggests when to use which imitation strategy (mimic, dislodge, or do nothing).

\section{$<$ Insert Figure 11 about here $>$}

Apart from being a concise summary of our findings, the decision tree highlights a number of interesting characteristics of imitation. First of all, complexity only plays a role in determining the most effective imitation strategy when there are similar peers to be imitated and the time horizon is longenough. This finding is noteworthy because even though it is well known that complexity harms the ability to imitate (e.g., Ounjian and Carne, 1987; Galbraith, 1990; Rivkin, 2000), we show that from the point of view of a firm deciding on the best imitation strategy, complexity only plays a role under specific conditions. The decision tree can also be used to state the following testable hypotheses regarding imitation (each hypothesis maps to one leaf of the decision tree, read from left to right). 
H1: When peer-similarity is low and the time horizon is short, performance is inversely related to the degree of imitation.

$\mathrm{H} 2$ : When peer-similarity is low and the time horizon is long, performance peaks at small degrees of imitation.

H3: When peer-similarity is high and the time horizon is short, performance increases as the degree of imitation increases.

H4: When peer-similarity is high, the time horizon is long, and complexity is low, performance increases as the degree of imitation increases, yet very high degrees of imitation may not be more beneficial than more moderate degrees of imitation.

H5: When peer-similarity is high, the time horizon is long, and complexity is high, performance peaks at intermediate degrees of imitation.

From a methodological standpoint this paper advances the simulation modeling of imitation. In particular, it incorporates two new elements: the creation of landscapes with varying degrees of similarity $(S)$, and the mechanisms to copy information among firms residing in different landscapes (discriminant and non-discriminant imitation).

We believe that this paper shows how agent-based simulation can be used as a disciplined way to develop theory. The simulation model allowed us to explore a terrain difficult to traverse using traditional techniques such as verbal theorizing, closed-form modeling, or empirical testing. Simulation forced us to be transparent about the assumptions and mechanisms present, and took care of correctly combining them to arrive at testable hypotheses. It is unlikely that verbal theorizing could have allowed us to do the same. Simulation does not replace empirical testing — but now, with a clear set of predictions at hand, makes it easier to devise effective empirical tests.

The results of our model also shed light on three previous disputes in the literature: the controversy between slow and fast learning, whether imitation is effective only at the start of operations or on a continuing basis, and whether firm similarity increases or decreases learning opportunities.

The controversy of slow learning (Levinthal and March, 1981; Herriott, Levinthal, and March, 1985; March, 1991) versus fast learning (Eisenhardt and Tabrizi, 1995) can be resolved if we realize that both sides assumed different environmental conditions. Eisenhardt and Tabrizi's examples are in complex and fast-paced industries (high-tech), while the others do not specify an industry. According to our model, fast 
learning (a high degree of imitation) is desirable in some environments (the cases marked as "mimic" in Figure 11), while slow learning is desirable in other environments (the cases marked as "dislodge" in Figure 11). Hence, it is not that slow learning is superior to fast learning or vice versa, but that the right strategy is context-dependent. It is interesting to note that our model qualifies the recommendation of Eisenhardt and Tabrizi: according to our model, fast-learning is advisable for complex and fast-paced industries only when there are similar firms to imitate. When no peers are available, our model would suggest resorting to individual, local search.

Some studies have found that organizations imitate more at the start of operations (Argote, Beckman, and Epple, 1990; Tyre and Orlikowski, 1994; Foster and Rosenzweig, 1995; Baum and Ingram, 1998), while other studies have found that imitation happens on a continuing basis (Darr, Argote, and Epple, 1995; Haunschild and Miner, 1997). Again, our model can shed light on this controversy: in industries where the landscape is continuously changing and there are similar peers (top row in Figure 5), broadscale imitation will continue to pay off as long as the environment continues to change, i.e., relevant time horizons remain short. On the other hand, in all other environments (bottom row in Figure 5 and whole Figure 10) we should not see extensive but more incremental imitation from peers on a continuing basis.

Finally, we try to reconcile the different views on the value of similarity. On the one hand, the supporters of the thesis of brokerage and structural holes (Burt, 1992) state that connecting firms with disparate knowledge bases may create valuable opportunities for exchanging knowledge. On the other hand, a different line of research states that firms may only learn from similar others (Daley, Mehotra, and

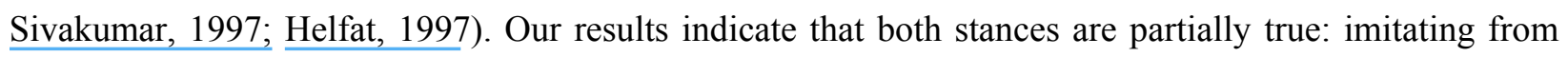
similar firms is valuable (as seen in Figure 5), and imitating from dissimilar firms is valuable when the landscape is relatively stable (as seen in the bottom row of Figure 10).

One important managerial takeaway is that even if firms set imitation at the most effective level, imitating similar firms can lead to much higher improvements than imitating dissimilar firms (as seen when comparing the peaks achieved in the top versus the bottom two panels in Figure 8). This is important, as in the real world firms may not know which firms are similar to them because similarity is 
costly to assess (e.g., the choice set may be large, be geographically disperse, or similarity may be not evident unless a deep analysis is carried out). Hence, it may be profitable for firms to strive to find similar peers before starting any imitative effort. This also points to a possible extension to our model: including a cost of assessing how similar is the focal firm to a potential target. This extension would allow exploring the optimal effort that should be allocated to uncover similar firms.

As every model, our simulation set-up has a number of limitations which point toward further future extensions. For instance, in our model it is assumed that managers do not have a good understanding of interaction effects. When firms imitate practices that interact with current practices, firms can only adjust their existing practices via local exploration. In reality, managers may have some idea of potential interactions. At the same time, they also may have some faulty ideas about interactions. The effects of cognitive limits in the understanding of interaction effects seems a ripe area for future research (see, for instance, Gavetti and Levinthal, 2000).

In sum, our present work offers four main findings - all of which have theoretical and managerial implications. First, imitation can serve two different functions. It can either be used to attempt mimicking the exact configuration of practices of other high-performing firms, or it can be used to dislodge a firm from its current set of practices, generating broader exploration. Second, an improvement of a firm's imitative capabilities is not always valuable. Large-scale imitation-even in the absence of competitive effects - is only valuable when firms imitate from very similar peers and if the time horizon is short. Third, in the presence of interactions among practices, the most effective imitation strategies differ dramatically depending on time horizon. The best strategy for long time horizons is actually the worst strategy for short horizons, while the best strategy for short horizons is not particularly valuable for long horizons. Fourth, imitation from dissimilar firms can be treacherous, especially for short time horizons. For long time horizons, small doses of imitation can, however, be helpful. In this case, it is not the direct imitation of a practice that is valuable, but the dislodging and subsequent search that can yield performance improvements in the long run. 


\section{References}

Argote, L. 1999. Organizational learning: Creating, retaining, and transferring knowledge. Kluwer Academic, Boston, MA.

Argote, L., Beckman, S. L., and Epple, D. 1990. The persistence and transfer of learning in industrial settings. Management Science 36(2): 140-154.

Baum, J. A. C. and Ingram, P. 1998. Survival-enhancing learning in the Manhattan hotel industry, 18981980. Management Science 44: 996-1016.

Bikhchandani, S., Hirshleifer, D., and Welch, I. 1998. Learning from the behavior of others: Conformity, fads, and informational cascades. Journal of Economic Perspectives 12(3): 151-170.

Bollingtoft, A. and Ulhoi, J. P. 2005. The networked business incubator: Leveraging entrepreneurial agency? Journal of Business Venturing 20(2): 265-290.

Burt, R. S. 1992. Structural holes: The social structure of competition. Harvard University Press, Cambridge, MA.

Cohen, W. M. and Levinthal, D. A. 1990. Absorptive capacity: A new perspective on learning and innovation. Administrative Science Quarterly 35: 128-152.

Cyert, R. M. and March, J. G. 1963. A behavioral theory of the firm. Prentice Hall, Englewood Cliffs, NJ.

Daley, L., Mehotra, V., and Sivakumar, R. 1997. Corporate focus and value creation: Evidence from spinoffs. Journal of Financial Economics 45: 257-281.

Darr, E. D., Argote, L., and Epple, D. 1995. The acquisition, transfer, and depreciation of knowledge in service organizations: Productivity in franchises. Management Science 41(11): 1750-1762.

DiMaggio, P. J. and Powell, W. W. 1983. The iron cage revisited: Institutional isomorphism and collective rationality in organizational fields. American Sociological Review 48: 147-160.

Efron, B. 1979. Bootstrap methods: Another look at the jackknife. Annals of Statistics 7: 1-26.

Eisenhardt, K. M. and Tabrizi, B. 1995. Accelerating adaptive processes: Product innovation in the global computer industry. Administrative Science Quarterly 40: 84-110.

Ethiraj, S. K. and Levinthal, D. A. 2004. Modularity and innovation in complex systems. Management Science 50: 159-173.

Ethiraj, S. K., Levinthal, D. A., and Roy, R. R. forthcoming. The dual role of modularity: Innovation and imitation. Management Science.

Foster, A. D. and Rosenzweig, M. R. 1995. Learning by doing and learning from others: Human-capital and technical change in agriculture. Journal of Political Economy 103(6): 1176-1209.

Galbraith, C. S. 1990. Transferring core manufacturing technologies in high-technology firms. California Management Review 32(4): 56-70.

Gavetti, G. and Levinthal, D. A. 2000. Looking forward and looking backward: Cognitive and experiential search. Administrative Science Quarterly 45: 113-137.

Gavetti, G., Levinthal, D. A., and Rivkin, J. W. 2005. Strategy making in novel and complex worlds: The power of analogy. Strategic Management Journal 26(8): 691-712.

Haunschild, P. R. and Miner, A. S. 1997. Modes of inter-organizational imitation: The effects of outcome saliency and uncertainty. Administrative Science Quarterly 42: 472-500. 
Haveman, H. A. 1993. Follow the leader: Mimetic isomorphism and entry into new markets. Administrative Science Quarterly 38(4): 593-627.

Helfat, C. E. 1997. Simple indicators of adaptation versus rigidity in history-dependent firm activities and decision rules. Industrial and Corporate Change 6: 49-75.

Herriott, S. R., Levinthal, D. A., and March, J. G. 1985. Learning from experience in organizations. American Economic Review 75: 298-302.

Kauffman, S. A. 1993. The origins of order: Self-organization and selection in evolution. Oxford University Press, New York.

Kogut, B. 1988. Joint ventures: Theoretical and empirical-perspectives. Strategic Management Journal 9(4): 319-332.

Lenox, M., Rockart, S., and Lewin, A. 2006. Interdependency, competition and the distribution of firm and industry profits. Management Science 52: 757-772.

Levinthal, D. A. 1997. Adaptation on rugged landscapes. Management Science 43(7): 934-950.

Levinthal, D. A. and March, J. G. 1981. A model of adaptive organizational search. Journal of Economic Behavior and Organizations 2: 307-333.

Lieberman, M. B. 2002. Did first-mover advantage survive the dot-com crash?, UCLA Anderson School of Management Working Paper. Los Angeles.

Lieberman, M. B. and Asaba, S. 2006. Why do firms imitate each other? Academy of Management Review 31(2): 366-385.

Lieberman, M. B. and Montgomery, D. B. 1988. First-mover advantages. Strategic Management Journal 9: 41-58.

Lippman, S. A. and Rumelt, R. P. 1982. Uncertain imitability: An analysis of interfirm differences in efficiency under competition. Bell Journal of Economics 13(2): 418-438.

March, J. G. 1991. Exploration and exploitation in organizational learning. Organization Science 2: 7187.

Marengo, L., Dosi, G., Legrenzi, P., and Pasquali, C. 2000. The structure of problem-solving knowledge and the structure of organizations. Industrial and Corporate Change 9: 757-788.

McEvily, S. K., Das, S., and McCabe, K. 2000. Avoiding competence substitution through knowledge sharing. Academy of Management Review 25(2): 294-311.

McKelvey, B. 1999. Avoiding complexity catastrophe in coevolutionary pockets: Strategies for rugged landscapes. Organization Science 10(3): 294-321.

Mill, J. S. 1848/2004. Principles of political economy. Prometheus Books, Amherst, NY.

Mowery, D. C. and Sampat, B. N. 1999. Patenting and licensing of university inventions: Lessons from the history of the Research Corporation.

Nutt, P. C. 1998. How decision makers evalutate alternatives and the influence of complexity. Management Science 44: 1148-1166.

Ounjian, M. L. and Carne, E. B. 1987. A study of the factors which affect technology-transfer in a multilocation multibusiness unit corporation. IEEE Transactions on Engineering Management 34(3): 194-201. 
Porter, M. E. 1996. What is strategy? Harvard Business Review 74(6): 61-78.

Rivkin, J. W. 2000. Imitation of complex strategies. Management Science 46: 824-844.

Rivkin, J. W. 2001. Reproducing knowledge: Replication without imitation at moderate complexity. Organization Science 12(3): 274-293.

Rivkin, J. W. and Siggelkow, N. 2003. Balancing search and stability: Interdependencies among elements of organizational design. Management Science 49: 290-311.

Schilling, M. A. and Phelps, C. 2006. Interfirm collaboration networks: The impact of large-scale network structure on firm innovation. Management Science(Forthcoming).

Siggelkow, N. 2002. Evolution toward fit. Administrative Science Quarterly 47: 125-159.

Simon, H. A. 1947. Administrative Behavior. MacMillan, New York, NY.

Simonin, B. L. 1999. Ambiguity and the process of knowledge transfer in strategic alliances. Strategic Management Journal 20(7): 595-623.

Staw, B. M. and Epstein, L. D. 2000. What bandwagons bring: Effects of popular management techniques on corporate performance, reputation, and CEO pay. Administrative Science Quarterly 45(3): 523556.

Szulanski, G. 1996. Exploring internal stickiness: Impediments to the transfer of best practice within the firm. Strategic Management Journal 17(Special issue: Knowledge and the firm): 27-43.

Tyre, M. J. and Orlikowski, W. J. 1994. Windows of opportunity: Temporal patterns of technological adaptation in organizations. Organization Science 5(1): 98-118.

Winter, S. G. 1995. Four Rs of profitability: Rents, resources, routines and replication. In C. Montgomery (Ed.): 147-178. Kluwer Academic, Boston, MA. 
Figure 1: Short-run and longrun performance for similar firms and low complexity

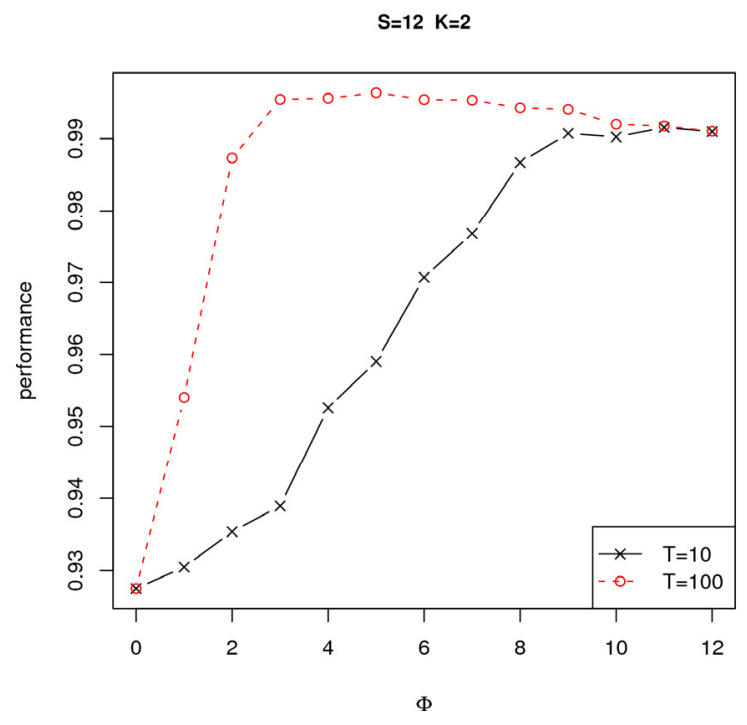

Figure 2: Short-run and long-

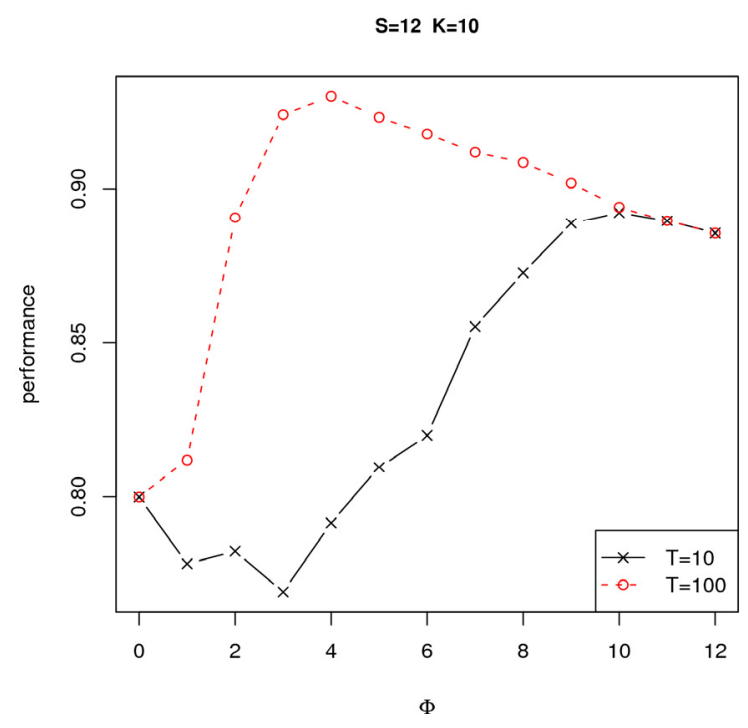
run performance for similar firms and high complexity 
Figure 3: Percentage of first imitations that end up decreasing performance

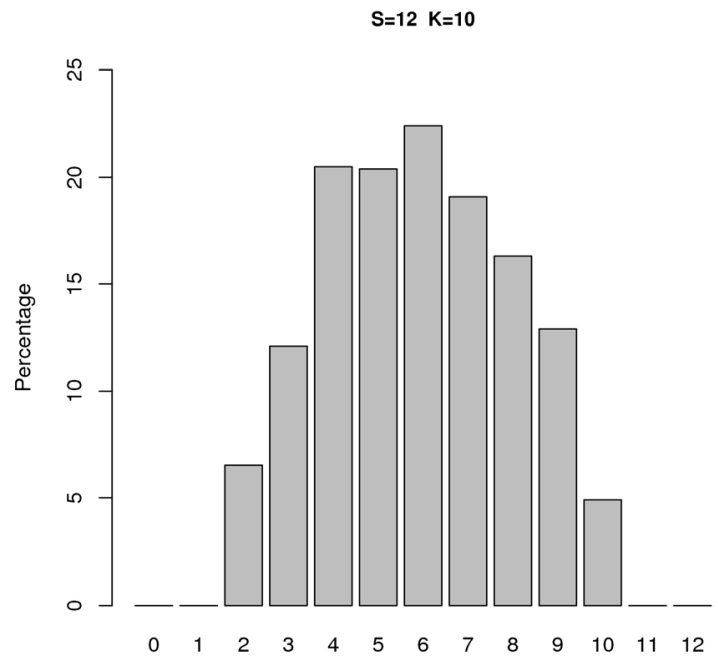

Note: Performance is measured from just before the first imitation to just before the second imitation

$S=12 \quad K=10$

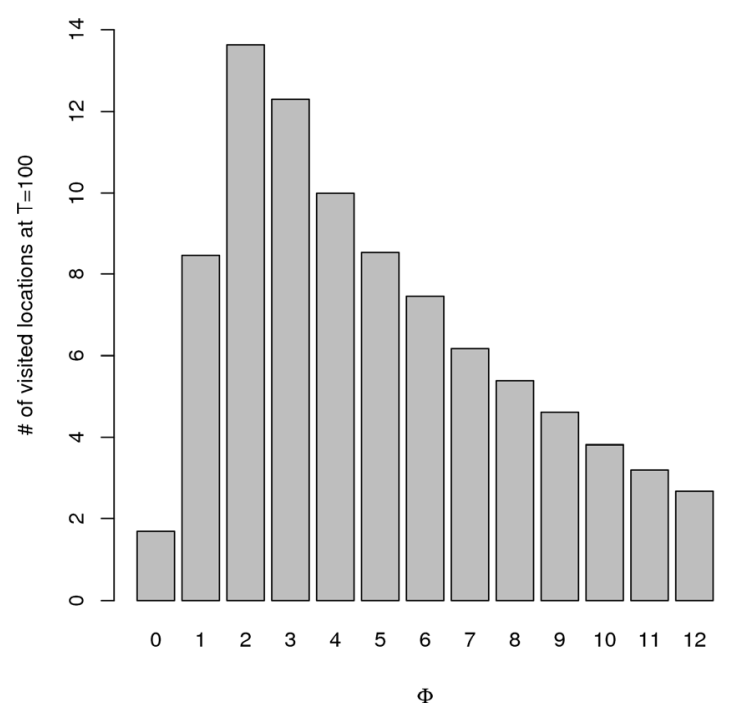


Figure 5: Most effective degree of imitation among similar firms as a function of Environmental Complexity and Time Horizon.
Figure 6: Short-run and longrun performance for dissimilar firms and low complexity
Figure 7: Short-run and longrun performance for dissimilar firms and high complexity
Environmental Complexity (K)

\begin{tabular}{|c|c|c|}
\hline & Low & High \\
\hline $\begin{array}{c}\text { Short Term } \\
\text { (Turbulence) }\end{array}$ & High Imitation & High Imitation \\
\hline $\begin{array}{l}\text { Long Term } \\
\text { (Stability) }\end{array}$ & $\begin{array}{l}\text { Intermediate or } \\
\text { High Imitation }\end{array}$ & $\begin{array}{l}\text { Intermediate } \\
\text { Imitation }\end{array}$ \\
\hline
\end{tabular}
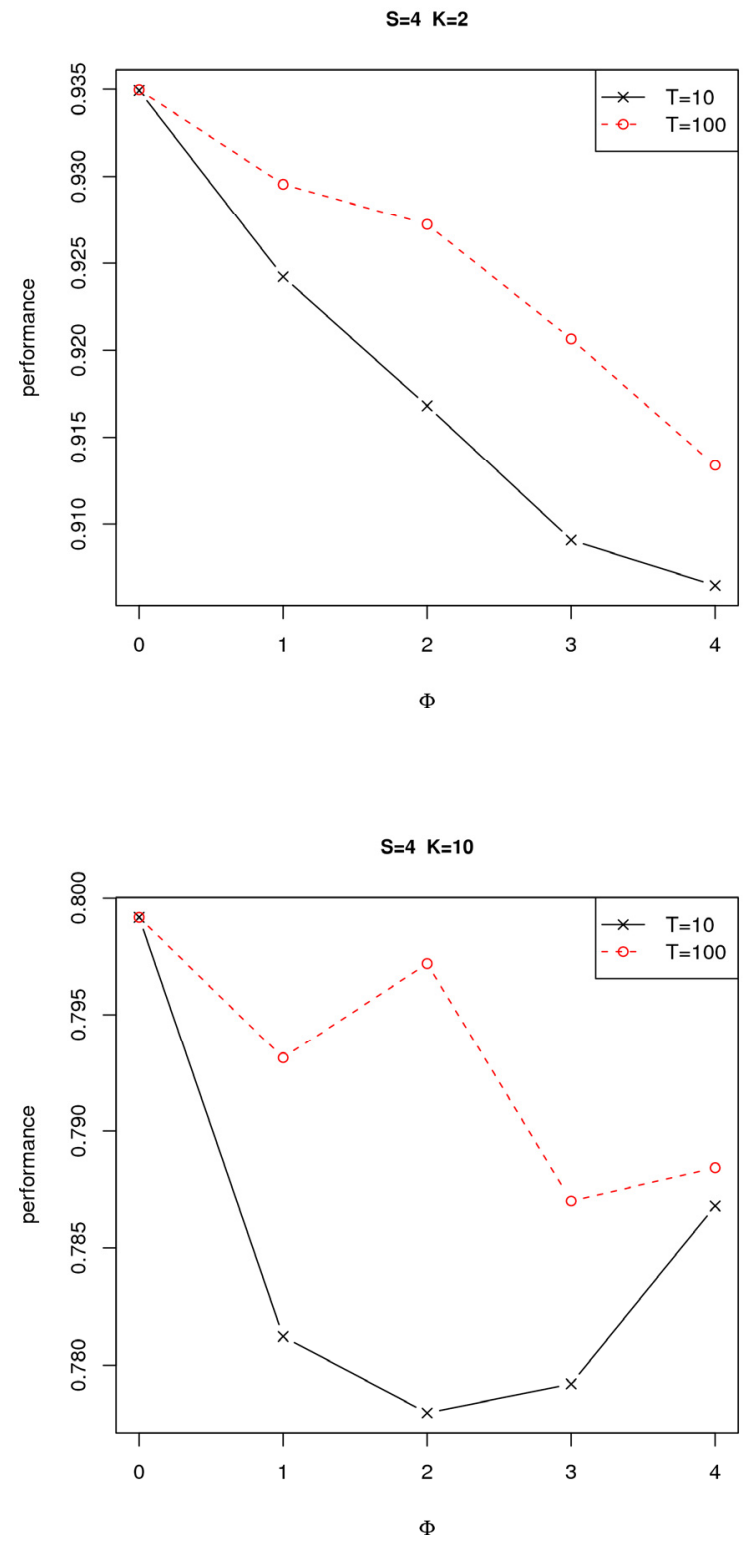
Figure 8: Results for firms using nondiscriminant imitation
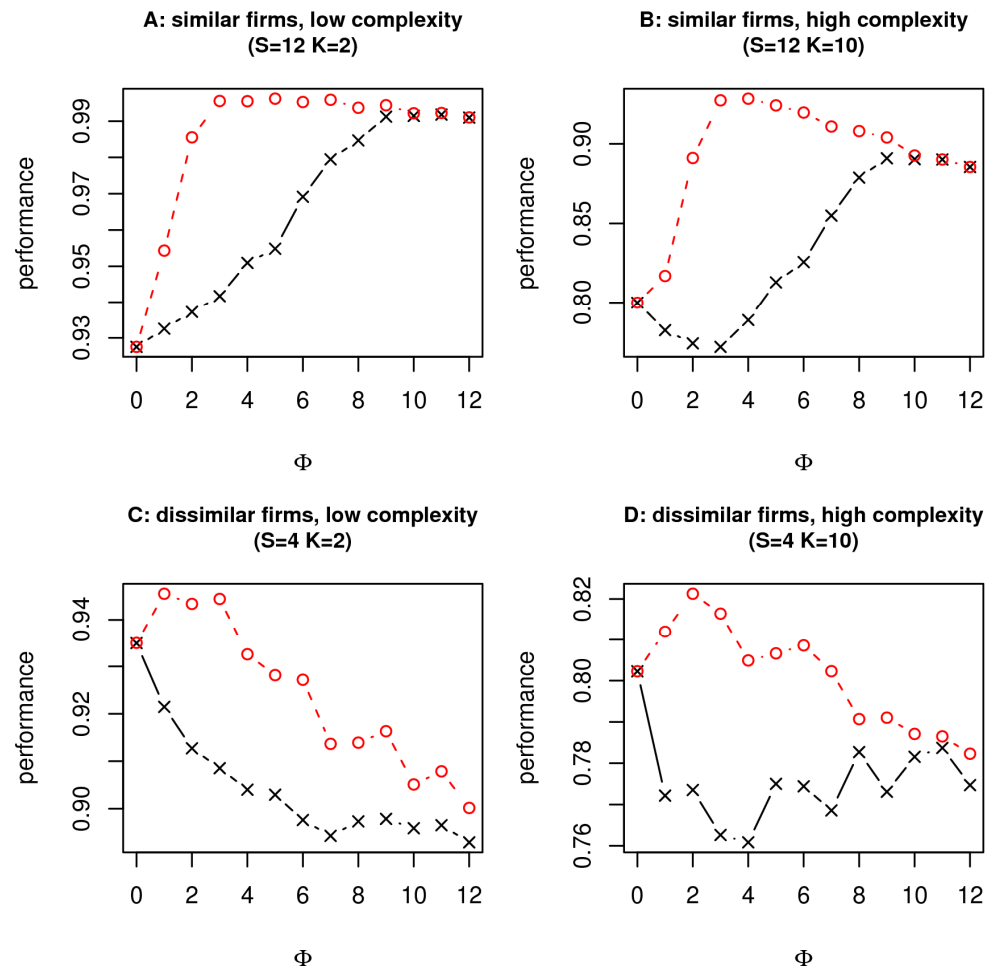

Figure 9: Average number of visited locations for dissimilar firms using non-discriminant imitation

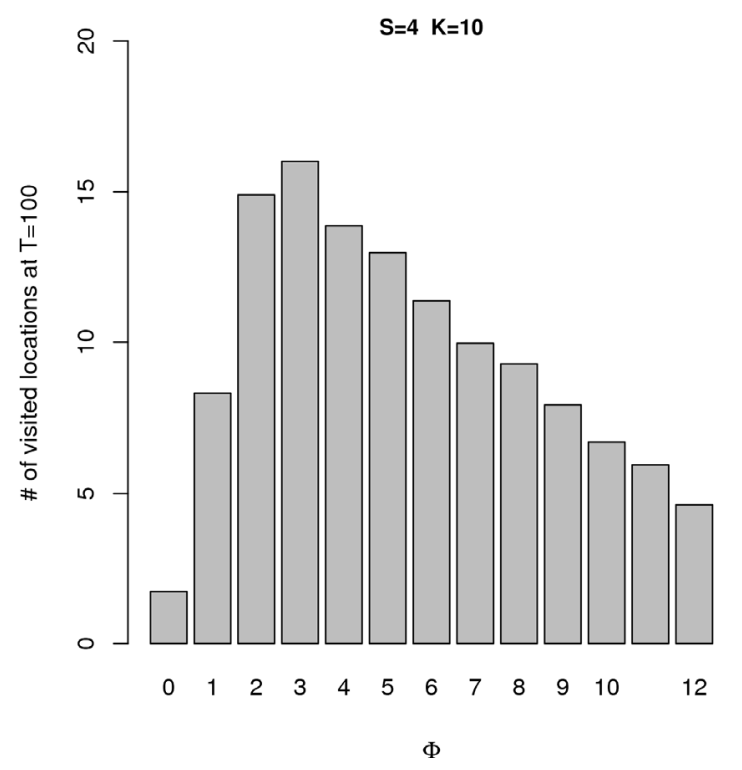


Figure 10: Most effective degree of imitation among dissimilar firms as a function of Environmental Complexity and Time Horizon.
Figure 11: Decision-tree to determine whether to mimic, dislodge, or to do nothing
Environmental Complexity (K)

\begin{tabular}{|c|c|c|}
\hline & Low & High \\
\hline $\begin{array}{c}\text { Short Term } \\
\text { (Turbulence) }\end{array}$ & No Imitation & No Imitation \\
\hline $\begin{array}{l}\text { Long Term } \\
\text { (Stability) }\end{array}$ & $\begin{array}{c}\text { Small, random } \\
\text { imitation }\end{array}$ & $\begin{array}{c}\text { Small, random } \\
\text { imitation }\end{array}$ \\
\hline
\end{tabular}

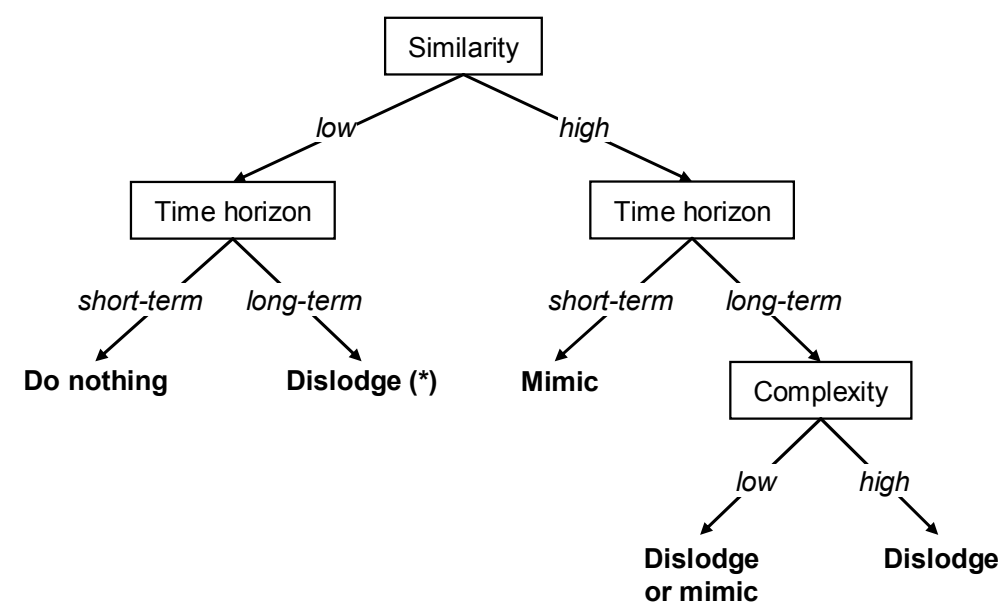

Note: The $(*)$ denotes that this is a non-discriminant imitation, as discussed in Section IV.3. 